\title{
Ethics and Semantic Change in Saudi Colloquial Speech
}

\author{
Fahd Shehail Alalwi ${ }^{1} \&$ Sayed Ismail ${ }^{2}$ \\ ${ }^{1}$ Assistant Professor of Linguistics and Dean of Preparatory Year Deanship, Prince Sattam bin Abdulaziz \\ University, Saudi Arabia \\ ${ }^{2}$ Assistant Professor of Translation Studies, Prince Sattam Bin Abdulaziz University, Saudi Arabia \\ Correspondence: Sayed Ismail, Assistant Professor of Translation Studies, Prince Sattam Bin Abdulaziz \\ University, Saudi Arabia. E-mail: a.ismail@psau.edu.sa
}

Received: June 20, 2019 Accepted: July 29, 2019 Online Published: August 20, 2019

doi:10.5539/ijel.v9n5p47 URL: https://doi.org/10.5539/ijel.v9n5p47

\begin{abstract}
The paper aims to provide insights onto the relationship between ethics and semantic change and how ethics could change the semantic values through tracing the historical development in meaning of selected lexical items in Saudi colloquial speech. The study starts from the hypothesis that there is a reciprocal connection between ethics and semantic change. It seeks to examine whether the common ethical values could result into changing the peripheral meaning of lexical items. In order to obtain more accurate and precise results about the effect of the ethics on the semantic shift in Saudi Arabic, the study applies a qualitative methodology through which it conducts an interview with more than thirty Saudi male and female belonging to different ages and different cultural backgrounds in order to get their feedback and response about their understanding of a set of chosen lexical items. The study has reached the finding that the common ethical values dominating a society can reshape the meaning of the lexical items into the minds of speakers.
\end{abstract}

Keywords: ethics, colloquial speech, lexical items, semantic change

\section{Introduction}

\subsection{The Research Problem}

The paper addresses the issue of semantic change in Saudi colloquial speech, as it traces the semantic development in moral words and expressions. To narrow the scope of the study, the paper analyzes the semantic change happens to moral words at the scale of vernacular speech. In other words, the study is meant to trace the meaning development of a set of lexical items in colloquial speech, as it tries to learn about how Fusha can be used in the everyday speech through highlighting the relationship between language and ethics. The colloquial speech is much more counterstained by the external realities surrounding the speaker where psychological, social and cultural elements contribute to shaping and reshaping the meaning of such words and expressions. The semantic change is closely related to polysemy where multiple senses are developed systematically from the original meaning of words and the newly developed meanings may be conceptually related to the original meaning, in what is known as family resemblance category (Lakoff, 1987, p. 316; Johnson, 1987, p. 193). This family resemblance category is represented in meaning chains (Taylor, 1995, p. 85). The idea is that these multiple meanings share conceptual framework which is mainly originated in the lexical item. However, the current study focuses on the semantic change that creates new meanings, which are totally different from the original lexical items, as they often manifest opposite concepts

\subsection{The Importance of the Problem}

This study is highly significant since it draws heavily on the invisible connection between language and ethics, which can represent a convincing answer for why many words of positive connotations have changed into negative words of low and degraded meaning. This study is mainly based on historical semantics approach which is viewed from a socio-historical dimension. In this respect, the study applies semantic foundation theory that explains the foundations of words meaning and their development, as the main objective of the study is to explain the causes for semantic change in moral words in colloquial speech in Saudi Arabia. Stalnaker (1997, p. 535) makes a related distinction between descriptive and foundational semantics.

On the one hand, A descriptive semantic theory is a theory that says what the semantics for the language is 
without saying what it is about the practice of using that language that explains why that semantics is the right one. Foundational theories, on the other hand, answer questions "about what the facts are that give expressions their semantic values, or more generally, about what makes it the case that the language spoken by a particular individual or community has a particular descriptive semantics."

The study draws heavily on the premise that ethical values contribute to changing the semantic value at the level of colloquial speech. As such, it tries to answer the following questions: (1) Can ethical values contribute to changing the semantic values at the level of the colloquial speech? (2) How could ethical values change the meaning of words at the level of colloquial speech? In this way, the study attempts to identify the causes of semantic change in Saudi colloquial speech.

\subsection{Relevant Scholarship}

The previous studies addressing the causes of semantic change are known for their generalization and abstract nature. Meillet (1974, p. 22) explains that social dialectal factors are among the most important causes of semantic change, as semantic change is activated through the social groups whose communicative system is the major cause of semantic change, which is fueled by various types of human interactions. In the same vein, Ullmann (1957, p. 171) argues that meaning is reproduced out of interrelated and renewed relationship between name and sense, as any change occurs to such a type of relationship would enforce the process of semantic change. This intertwined relationship is fueled by all forms of oral communication. Kleparski $(1988,1990)$ discusses the semantic change in negatively loaded lexical items, which are related to human body and provides important remarks on the semantic degradation.

Such a type of causal relationship between semantic change and circumstantial realities would reflect that idea that lexical items in themselves are just lifeless objects that derive their senses from people's perception of the function of the word in relation to something else. This would bring us to an important finding that semantic change is relational in nature in which the newly developed meanings are invented and renewed in relation to a new existing reality, which has something in common with the existing realities. According to Rayevska (1979, $\mathrm{p}$. 130), this process pertains to those words that have precise denotation (specific names for things), however, during their history, the words lose their denotation and the word's meaning becomes extended and generalized. However, the idea of narrowing is meant to narrow the use of a broad term and turns it into a a specialized word.

\section{Method}

This study uses historical semantic framework of analysis known as historical-philological semantics as an approach through which it examines diachronically lexical semantics in order to stress the dynamic nature of the semantic values. The study focuses on the pejoration of meaning as a typology of the patterns of change. It adopts Stetkevych's method which explains that meaning change is related to our conceptualization of our world, which is driven by speakers' interests and needs. Through resorting to the historical semantic framework of analysis, the study focuses on tracing the pejoration of meaning in certain moral words in contemporary Saudi dialect. The Saudi dialect is an urban spoken vernacular, which is semantically different from Fusha. The Saudi dialect is changeable due to its oral nature that derives its semantic values from its surrounding reality and worldview. These renewed socioeconomic realities of Saudi Arabia have largely contributed to changing the semantic values of Saudi dialectal terms and expressions. The data of this paper are based on field notes where more than thirty Saudis representing different ages were asked many questions in order to get their feedback about their understanding of various moral words and expressions. The mechanism of the interviews has focused on taking notes of the firsthand response of the interviewed groups. The questions being exposed in the interview have focused on testing the sense of the moral terms and expressions and how they are articulated and reported by the interviewed communities. The addressed questions were designed to meet the cultural, age, education, and social status of the interviewed, as the questions were distributed to people from different ages, different cultural backgrounds, different education backgrounds. These questions considered the tribal affiliations and whether the interviewed live in Bedouins or urban areas. The questions are generally focused on moral words and how the modern Saudi people representing various sects could perceive these words, and the socio-demographic realities are considered when addressing the questions. Qualitative analysis is appropriate for the purpose of the study as it is ideally suited for exploring people's attitudes, opinions, beliefs, perceptions, interactions and behaviors in various settings and where the approach is interpretative and the data are presented subjectively rather than statistically (Creswell, 2013; Yin, 2014). Furthermore, qualitative analysis enables researchers to seek an in-depth understanding of a particular entity, individual or event at a specific time, with a focus on a particular unit of analysis (Creswell, 2009, 2013). 


\section{Finding, Analysis and Discussion}

The results of this study are derived from the feedback of the interviewed participants who expressed their firsthand response toward their understanding of a selected set of moral words, and how their present understanding is different from the traditional meaning of the word. However, the study focuses on getting their feedback regarding their understanding of the meaning of these words in colloquial speech. It draws on tracing historically the semantic change of a set of classical Arabic words and how different is their meaning from the past to the present. Stevick $(1968$, p. 267) states that semantic change results from changing attitude toward the elements of content of the words with which expressions are associated. Anis (1976, p. 140) remarks that that political conditions may contribute to degrading the meaning of certain words including social and political ranks which have been socially and culturally disappeared from the scene. Their diminishing reality results into the pejoration of their meanings. For example, "pasha" is a Turkish title given in the Arab world to the landlords who owned large properties and real estates. When this social structure of the feudal system in the Arab world has come to an end, the word pasha was degraded to be given to any person of low social status. Sometimes, in Saudi vernacular speech, it is used to mock people. He further argues that psychological and emotional conditions of the collective minds of the speakers represent the major causes of semantic degradation. This can be clearly reflected from the response of the interviewed people regarding their understanding and reception of moral words like, "häbib". "Häbib" is a moral word, which has an explicit positive connotation in Fusha. In Lisan Al'arab, it is derived from the Arabic root " $h \bar{a} b$ ", which means "to love". It can be treated as an adjective that means "beloved" or "lovely" or it can be past participle, which means "loved one". This word manifests positive connotations. However, the responses of the interviewed people have unanimously agreed that this word in Saudi vernacular speech refers to naïve and foolish man. It would be clear that the meaning pejoration results in a deeper difference between signifier and signified. However, Ibn Jini (2006) states that there is a mutual and deeper connection between signified and signifier. There is a relationship between the content of meaning and its perception in speaker's mind.

He argues that word "musk" which means "Arabian perfume' is derived from the Arabic verb "mask" to hold. It was given such a name "musk" because it holds and attracts the sense of smell to its fragrance. In the same vein, Ibn Faris (1946) asserts that Arabic language shows such a mutual liaison between signifier and signified. Similarly, in the Egyptian dialect or vernacular speech, the word "tayaib", which means "good", "virtuous", and "kind". However, in the contemporary Egyptian vernacular speech, it has been stripped off its positive connotations and instead, it means "naïve" and "foolish man" (Ismail, 2017).

The historical development of words like "häbib" has been always loaded with absolutely positive connotations. The contemporary sense of the word in Saudi vernacular speech refers to totally opposite meaning, full of negativity and passivity, which is equivalent to foolishness and stupidity tinged with a mockery and satire. The important issue in such a case rests upon the idea that the pejoration of meaning has been manifested in vernacular speech and dialect. Ul-fușhá keeps the positive sense of the word unchanged. What is more striking, according to the results obtained from the interview, is that people belonging to different sexes, different ages, different cultural and educational backgrounds hold a similar view about the negative connotations implied in the word.

Another word that shows the degradation of ethical and moral word is "ibn hälāl" which refers to "dutiful son", "kind man", "good hearted". In Saudi vernacular speech, it means "mentally retarded person". In Fusha, "äjüdi" means a generous and hospitable man. In Saudi vernacular speech, it means "naïve". In Fusha, "kharuf", which means sheep, is traditionally related to innocence, purity, redemption, obedience and peace. In Saudi vernacular speech, it means a henpecked man. The word "šaykh", originally refers to an elderly man who is highly respected in society and Muslims jurists and scholars have been given this title. However, it has been recently degraded to be used as a title for mocking people.

The degradation in meaning of aforementioned words can be attributed to two major causes, which are closely interdependent. The first major cause is the norms of socialization prevailed over a society and the second is the attitudes and ideologies of the speakers. "Discussions of its relationship to ideology often fail to acknowledge that language is not simply a vehicle for other ideological processes but is itself shaped by ideological processes" (Cameron, 2006, p. 141). The attitudes of the individuals in a certain society are largely influenced by the norms of the prevalent social values, and relations. These social norms, value systems and ethics would considerably shape and reshape peoples' attitudes, which are ultimately manifested in their use of language and their perception of linguistic expressions and their reception of words and how their minds could shape different connotations, which largely agree with such a changing reality and the changing value system. People's attitudes, value system and ideology are constituted out of their social behavior and their social relation and their world 
view which have their reflection on their digestion, use, articulation and perception of the content of the words. A striking remark is that materialistic values have prevailed over the Arab societies, which is evidenced through tracing the degraded of meaning of one category of words lumped together under the moral lexicons. To put it in another words, expressions and terms like "häbib", "tayaib", "ibn hầlât", "äjūidi" and "kharuf" express absolutely humanistic values and share spirituality and tolerance and mutual respect. In a more materialistic societies, such values of spirituality, tolerance and love are clear sign of weakness and vlunarblity, which is psychologically rejected in societies the members of which hold ardent belief in materialism and selfishness.

\section{Conclusion}

It seems to be that semantic change of moral words in Saudi vernacular speech is largely affected by prevalent modes of culture, morality, ideology and societal values. These values represent major part of speaker's perception of the external realities, which would constitute the mental representation of word meaning. When value system and culture and ethics are deteriorated and degraded, this would make people strip moral words off their positive meanings and replace the positive meaning by totally negative and degraded connotations. The surrounding conditions and the circumstantial realties and the dominating cultural values, the socioeconomic realities impose different realities that make words acquire new connotations, which are mostly negative in order to make language consistent with its surrounding realities. In this way, the causes of semantic change can be represented in morality, attitude, societal values, and psychological nature of people themselves. If these values are degraded, speakers' use of language will be automatically deteriorated. When societies look down at good human traits like kindness and politeness and consider them features of human weakness and vulnerability, the positive meanings implied in these words will automatically turn into negativity. In such a case, meaning lies within the confines of our perception of our own contemporary world; it is no longer received from dictionaries; however, it is derived from our reaction and interaction to the surrounding realities. When goodness is classified by the contemporary societal values and dominating ethical values as a human weakness, speakers will unconsciously perceive it as a sign of naivety and foolishness.

\section{Funding}

The research for this article was supported by a grant from Prince Sattam Bin Abdulaziz University, Kingdom of Saudi Arabia, under grant no. 2017/02/6923.

\section{References}

Anis, I. (1976). Dālālat Al- 'alfadh. Cairo: Anglo Publishing House.

Cameron, D. (2006). Language and Ideology. Journal of Political Ideologies, 11(2), 141-152. https://doi.org/10.1080/13569310600687916

Creswell, J. W. (2009). Quantitative \& Qualitative Research. Thousand Oaks, CA SAGE.

Creswell, J. W. (2013). Research Design: Qualitative, Quantitative, and Mixed Methods Approaches. London: SAGE.

Ibn Faris, A. (1946). Maqayis 'alugha. Cairo: Dar Alfikr.

Ibn Jini, A. (2006). Al-khasais. Cairo: Egyptian Ministry of Culture.

Ibn Manzūr, in Lisān al-Arab. Retrieved from https://www.maajim.com/dictionary

Ismail, A. (2017). Hermeneutics and the Problem of Translating Traditional Arabic Text. New Castel: Cambridge Scholars Publishing.

Johnson, M. (1987). The Body in the Mind. The Bodily Basis of Meaning, Imagination and Reason. Chicago: Chicago University Press. https://doi.org/10.7208/chicago/9780226177847.001.0001

Kleparski, G. A. (1988). Semantic Change and Semantic Components: A Study of English Evaluative Developments in the Domain of HUMANS. Unpublished Ph.D. Dissertation, The Catholic University of Lublin.

Kleparski, G. A. (1990). Semantic Change in English: A Study of Evaluative Developments in the Domain of HUMANS. Lublin: The Catholic University of Lublin Printing House

Lakoff, G. (1987). Women, Fire and Dangerous Things. What Categories Reveal about the Mind. Chicago: Chicago University Press. https://doi.org/10.7208/chicago/9780226471013.001.0001

Meillet, A. (1974). Wie die Wrter ihre Bedentung ändern. In G. Dinser (Ed.), Zur Theorie der Sprachveränderung (pp. 19-67). 
Rayevska, N. M. (1979). English Lexicology (4th ed.). Kiev: Vysca Skola Publishers.

Stalnaker, R. (1997). Reference and Necessity. In C. Wright \& B. Hale (Eds.), A Companion to the Philosophy of Language (pp. 534-554) Oxford: Blackwell.

Stern, G. (1931). Meaning and Change of Meaning: With Special Reference to the English Language. Indiana: Indiana University Press 。

Stetkevych, J. (2006). The Modern Arabic Literary Language: Lexical and Stylistic Developments. Washington DC: Georgetown University Press.

Stevick, R. D. (1968). English and Its History: The Evolution of Language. Boston: Allyn and Bacon, Inc.

Taylor, J. (1995). Linguistic Categorisation, Prototypes in Linguistic Theory. Cambridge: Cambridge University Press.

Ullmann, S. (1952). Words and Their Use. New York: Philosophical Library, Inc.

Ullmann, S. (1957). The Principles of Semantics. Glasgow: Jackson, Son and Co.; Oxford: Basil Blackwell (2nd ed.)

\section{Copyrights}

Copyright for this article is retained by the author, with first publication rights granted to the journal.

This is an open-access article distributed under the terms and conditions of the Creative Commons Attribution license (http://creativecommons.org/licenses/by/4.0/). 